\title{
T6: THE OXFORD UNIVERSITY STALKER TUNNEL
}

\author{
Matthew McGilvray ${ }^{(1)}$, Luke Doherty ${ }^{(1)},{\text { Richard } \text { Morgan }^{(2)} \text { \& David Gildfind }}^{(2)}$ \\ ${ }^{(1)}$ University of Oxford, Department of Engineering Sciences, Parks Rd, Oxford, OX1 3PJ, United Kingdom \\ Email:matthew.mcgilvray@eng.ox.ac.uk \\ ${ }^{(2)}$ University of Queensland, School of Mechanical \& Mining Engineering, St Lucia, 4072, QLD, Australia \\ Email:r.morgan@uq.edu.au
}

\begin{abstract}
The University of Oxford has embarked on developing the UK's fastest wind tunnel, T6, in collaboration with the University of Queensland (Australia) using technology pioneered by the late Professor Ray Stalker. The T6 facility couples the ex-Australian National University $\mathrm{T} 3$ free piston driver to the barrels, nozzles and test section of the Oxford gun tunnel. The facility can operate in three different modes; as a shock tube, a reflected shock tunnel or as an expansion tunnel. The T6 facility will be unique to Europe allowing for hypervelocity ground testing not possible in any current EU facilities, whilst having the flexibility to conduct tests across a large range of speeds and binary scaling products $(\rho L)$ of interest.
\end{abstract}

\section{INTRODUCTION}

High speed vehicles are characterised by extremely high heat fluxes, non-ideal gas behaviour and shock dominated flow fields. The fundamental physics involved are often complex and large gaps exist in the current knowledge base. Vehicle geometries cover a wide range, from blunt planetary probes to slender atmospheric flight vehicles and flight testing, if not impossible pre-mission, is prohibitively expensive. For this reason ground based verification of proposed designs and computation codes remains crucial for the successful development of high speed flight vehicles.

During re-entry into Earth's atmosphere on a sub-orbital vehicle (such as the space shuttle) the peak heating experienced by the vehicle occurs at a speed of approximately $6 \mathrm{~km} / \mathrm{s}$. As shown in Fig. 1, at this velocity the flow at the stagnation point is well above the dissociation limit for both nitrogen and oxygen leading to complex chemistry in the post-shock region. Furthermore, re-entry from super-orbital conditions, such as those encountered during the Apollo missions or in proposed future missions to Mars experience much higher speeds, result in ionisation of the flow in the post-shock region.

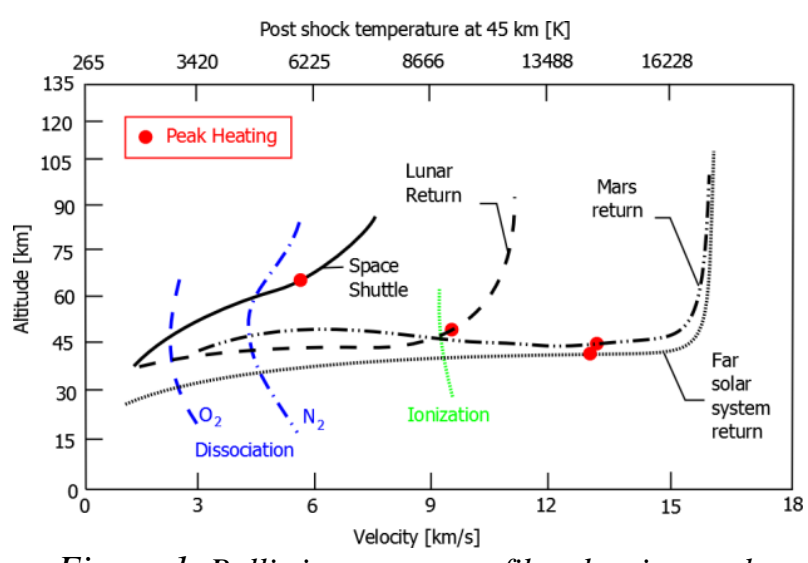

Figure 1. Ballistic re-entry profiles showing peak heating and initial location of chemistry effects. Data taken from [1].

The flight corridor for an air breathing hypersonic cruise or accelerator vehicle is shown in Fig. 2. In comparison with re-entry trajectories, which are restricted by the allowable heat load, the altitude of an air breathing hypersonic vehicle has a lower bound that is set by vehicle structural limits (typically taken to correspond to a dynamic pressure of $96 \mathrm{kPa}$ ) and an upper bound that is set by the need to sustain combustion (typically taken to correspond to a dynamic pressure of approximately $24 \mathrm{kPa}$ ).

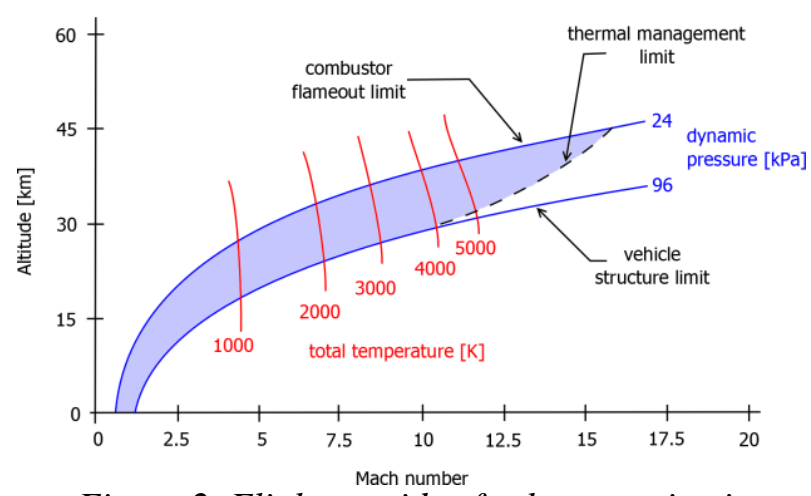

Figure 2. Flight corridor for hypersonic air breathing vehicles. 
Irrespective of the vehicle of interest, above approximately Mach 8, the creation of the extreme stagnation conditions needed for aerodynamic testing of bodies at hypersonic conditions requires the use of impulse type facilities. This is a consequence of both the energy input required to generate these conditions and the subsequent difficulty in containing the gas at very high pressures and temperatures. Impulsive shock facilities, which include shock tunnels, reflected shock tunnels and expansion tunnels have been the only facilities to practically create high total enthalpy hypersonic flows. In Europe however, few high enthalpy facilities exist that are able to test aerodynamic models above $3 \mathrm{~km} / \mathrm{s}$. The two significant facilities that do exist are in Germany: the HEG facility in Göttingen and the HELM facility in Munich.

This paper describes the development of a new multimode Stalker Tunnel that is being developed within the Osney Thermofluids Laboratory at the University of Oxford. Known as T6 the new facility will be uniquely versatile in Europe, permitting ground testing across a wide range of Mach numbers and enthalpies. The T6 facility couples the Prof. Ray Stalker designed T3 driver with the barrels, nozzles and test section of the Oxford Gun Tunnel. Each of these historic facilities is briefly described below. In addition, this paper discusses the performance of the free piston driver, the three operational modes (reflected shock tunnel, shock tube and expansion tunnel) and describes the associated infrastructure, instrumentation and data acquisition capability. In particular, focus is placed on the facilities capability to perform radiation and air-breathing engine studies.

\section{HISTORICAL PERSPECTIVE}

\subsection{T3 Stalker Tunnel}

Prof. Raymond Stalker, AO first conceived the free piston driven reflected shock tunnel, aka the Stalker shock tunnel in 1959 while at the National Research Council (NRC) in Canada. T3 was subsequently designed and built at the Australian National University (ANU) in 1968 and was the first in a series of large scale Stalker tunnels which includes T4 at The University of Queensland (UQ), Australia; HEIST at the Japan Aerospace Exploration Agency (JAXA) Kakuda Space Center; HEG at DLR, Göttingen; T5 at the California Institute of Technology (Caltech) and HELM at the University of Munich, Germany.

Shown in Fig. 3, T3 was capable of generating nozzle supply conditions up to $50 \mathrm{MPa}$ and $40 \mathrm{MJ} / \mathrm{kg}$. It featured an inline reservoir with volume $2.1 \mathrm{~m}^{3}$, a $5.8 \mathrm{~m}$ long compression tube with an internal diameter of 300 $\mathrm{mm}$ and a $7.7 \mathrm{~m}$ long shock tube with an internal diameter of $76.2 \mathrm{~mm}$. The free piston driver was made from stainless steel and was designed for a maximum rupture pressure of $250 \mathrm{MPa}$. One of two pistons was used in the facility, a 'light' piston with a mass of $36 \mathrm{~kg}$ and a heavier piston with a mass of $90 \mathrm{~kg}$; neither piston featured brakes.

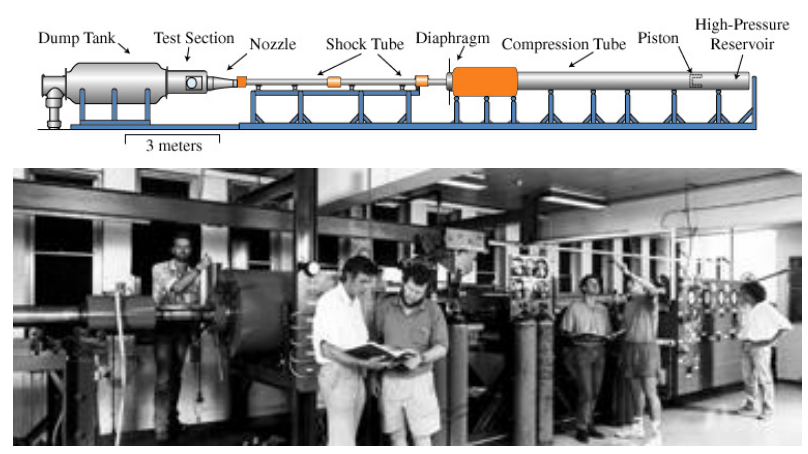

Figure 3. (Top, source unknown) A schematic of the T3 Stalker Tunnel. (Bottom, source unknown) The T3 Stalker Tube installed at the Australian National University circa 1970.

The T3 facility was used extensively throughout the 1970s and 1980s by Sandeman, Hornung, and Stalker [2] to undertake fundamental studies in high total enthalpy flow phenomena. The facility was decommissioned in the early 2000s whereupon it was purchased by Don Fry and stored at the UQ vet farm until 2014 when the University of Oxford purchased the compression and driver tube assembly.

\subsection{Oxford Gun Tunnel}

The Oxford Gun Tunnel was originally designed and built by Bristol Sidley Engines who used the tunnel to investigate sustained hypersonic flight. The facility was also used during the development of the Bloodhound missile. In the mid-1970s the facility was moved to the University of Oxford where it was used by Jones, Cain and Matthews for cold aerodynamic studies, including scramjet intake performance studies [3], rocket plume interaction studies [4] and investigations of the Beagle II lander [5]. Shown in Fig. 4 and Fig. 5, the Oxford Gun Tunnel consisted of an inline reservoir that was $5.49 \mathrm{~m}$ in length with an internal diameter of $361 \mathrm{~mm}$ and a $9.14 \mathrm{~m}$ length driven tube that was $96.3 \mathrm{~mm}$ in diameter. The lightweight piston had a mass of just $0.096 \mathrm{~kg}$.

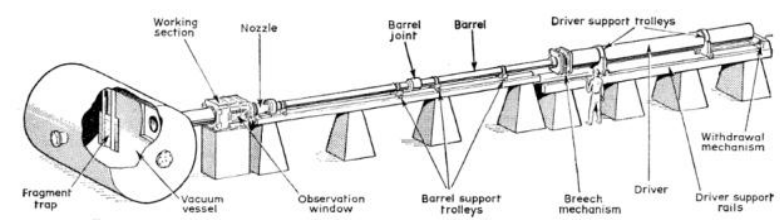

Figure 4. Schematic of the Oxford Gun Tunnel taken from [6]. 


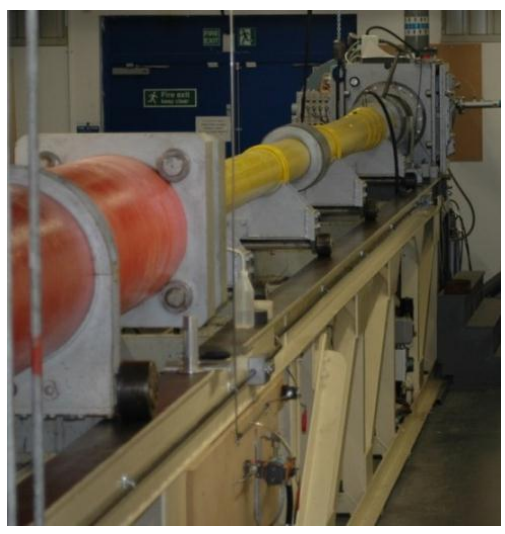

Figure 5: The Oxford Gun Tunnel Installed at the Osney Thermofluids Laboratory circa 2013.

\section{T6 STALKER TUNNEL}

The T6 Stalker Tunnel has recently been constructed at the Osney Thermofluids Laboratory at the University of Oxford. Funding for the facility has been provided by the UK Engineering \& Physical Sciences Research Council (EPSRC) as a part of the National Wind Tunnel Facility (NWTF) scheme. Development of the facility has been a joint collaboration between the University of Oxford and the University of Queensland's Centre for Hypersonics. The T6 facility, as shown in Fig. 6, is formed by coupling of the decommissioned $\mathrm{T} 3$ free piston driver to the barrels, nozzle and test section of the

Oxford Gun Tunnel. The result is a high performance reflected shock tunnel that can also be operated as either an expansion tunnel for the generation of super-orbital flow conditions or as a shock tube for examining shock layer radiation phenomena. The leading dimensions of the facility are presented in Tab. 1 . The achievable test flow duration, core flow size and maximum flow speed for each operating mode is presented in Tab. 2. The T6 Stalker Tunnel is the only high enthalpy wind tunnel in the UK and when operated in expansion tunnel mode will be the fastest facility in Europe.

Table 1: Dimensions of the main components of the T6 Stalker tunnel.

\begin{tabular}{|l|c|c|}
\hline Component & Length [m] & $\begin{array}{c}\text { Diameter } \\
{[\mathbf{m m}]}\end{array}$ \\
\hline Reservoir & 3.5 & 300 \\
\hline Driver & 6 & 300 \\
\hline Orifice Plate 1 & 0.01 & 76.2 \\
\hline Driven tube 1 & 1.75 & 96.3 \\
\hline Driven tube 2 & 4.25 & 96.3 \\
\hline Straight extension & 1.75 & 96.3 \\
\hline Mach 6 nozzle & 1.5 & 19.6 (throat) \\
& & 200 (exit) \\
\hline Mach 7 nozzle & 1.5 & 19.6 (throat) \\
& & 230 (exit) \\
\hline Mach 8 nozzle & 1.5 & 270 (exit) \\
\hline
\end{tabular}

\section{T6 - Oxford University Stalker Tunnel}

FIRING POSITION

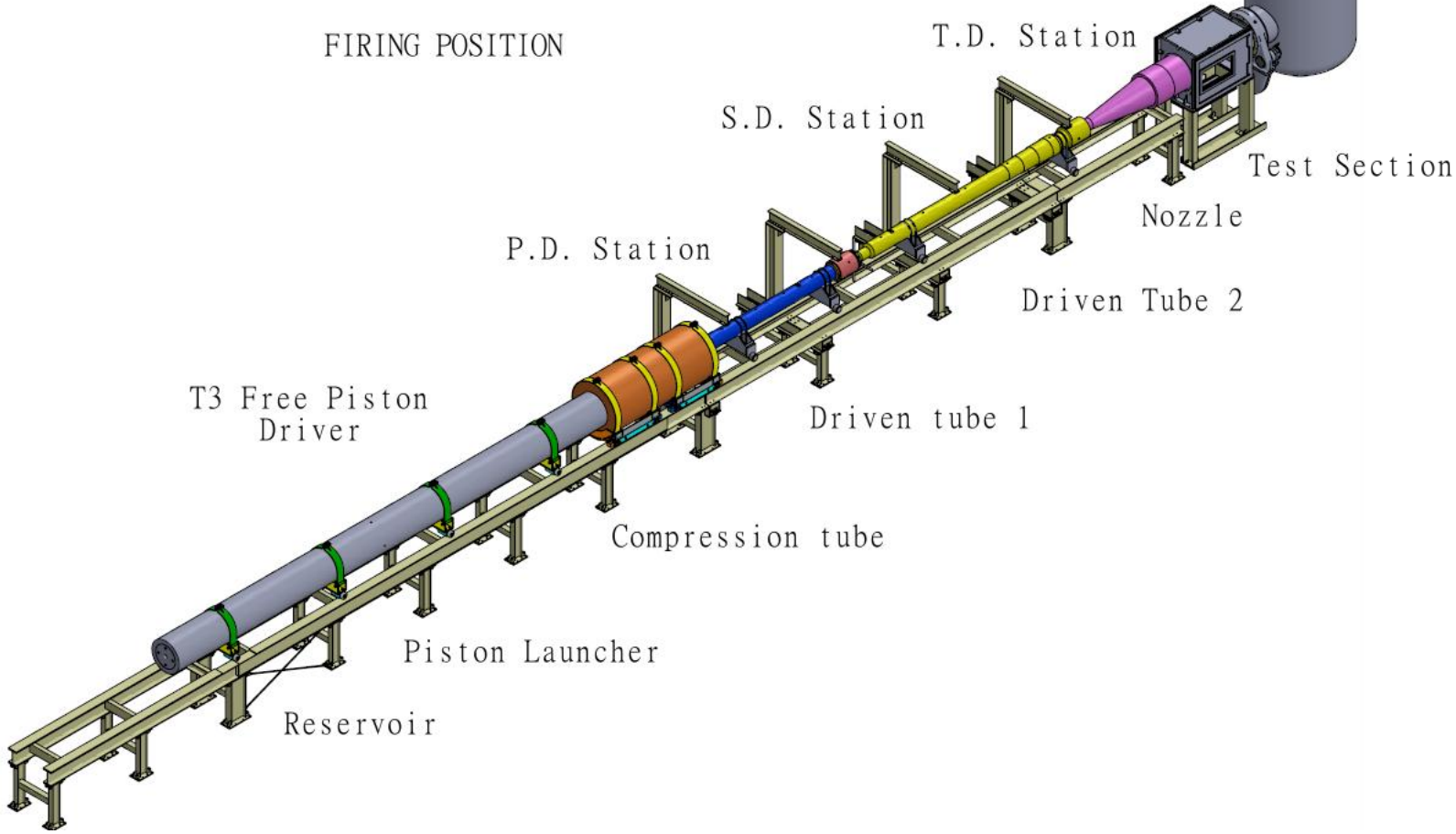

Figure 6: CAD Schematic of the T6 facility setup in reflected shock tunnel mode in firing position. 


\subsection{Free piston driver}

Hypersonic ground test facilities require extremely large amounts of energy. This has led to the development of transient facilities which create short duration flows at appropriate conditions. The generation of high total enthalpy conditions requires that a light gas be used at high pressures and temperatures (10's-100's of MPa and 1000 's of degrees K) to drive the process downstream. Furthermore, this slug of driver gas needs to be long enough to ensure that the test time is not limited by the reflection of expansion waves.

A Stalker free piston driver [7] is advantageous as it creates the heated gas using a transient compression process, thus containment of the high pressure and temperature gas is required for only a very short time thereby reducing the mechanical and thermal design constraints. The driver gas is compressed via a free piston stroke to the rupture pressure of the primary diaphragm. Although small slug lengths are obtained at the end of the process, careful attention to piston dynamics with the help of orifice plates can result in a very long effective driver length. Essentially this is achieved by ensuring that the piston is moving at an appropriate speed at primary diaphragm rupture to balance the mass loss out of the driver. This has the added benefit of minimising the amount of light gas required (typically Helium, as Hydrogen has safety concerns within a University setting).

To demonstrate the potential performance over other driver options, a driver condition that was previously used in the T3 facility is examined here to determine its capability for driving a $10 \mathrm{~km} / \mathrm{s}$ shock speed in air; a shock speed which is of interest for shock layer radiation studies related to earth re-entry. One previous T3 driver condition featured a rupture pressure $\left(p_{r}\right)$ of $50 \mathrm{MPa}$ at a volumetric compression ratio $(\lambda)$ of 60 with a $100 \%$ helium driver. This condition gives a temperature $\left(\mathrm{T}_{\mathrm{r}}\right)$ and sound speed $\left(\mathrm{a}_{\mathrm{r}}\right)$ at diaphragm rupture of $4600 \mathrm{~K}$ temperature and $4035 \mathrm{~m} / \mathrm{s}$ respectively. Taking the flow speed to be approximately equal to the shock speed, for a shock speed of $10 \mathrm{~km} / \mathrm{s}$ the flow equivalent Mach number is 2.5. Fig. 7 shows that the performance of a single piston compression driver is an order of magnitude better than a conventional combustion driven driver. Coupling a single piston to a secondary driver (compound) gives an extra order of magnitude increase in performance at this flow equivalent Mach number. This means that for the assumed rupture pressure of $50 \mathrm{MPa}$, the maximum initial pressure that can be achieved for a $10 \mathrm{~km} / \mathrm{s}$ shock is 0.07 torr, 0.35 torr and 1.75 torr respectively for each driver (combustion, single piston and single piston with secondary driver). Furthermore, by utilising an area change at the primary diaphragm (Fig. 8), an additional 25 times increase in performance can be achieved.

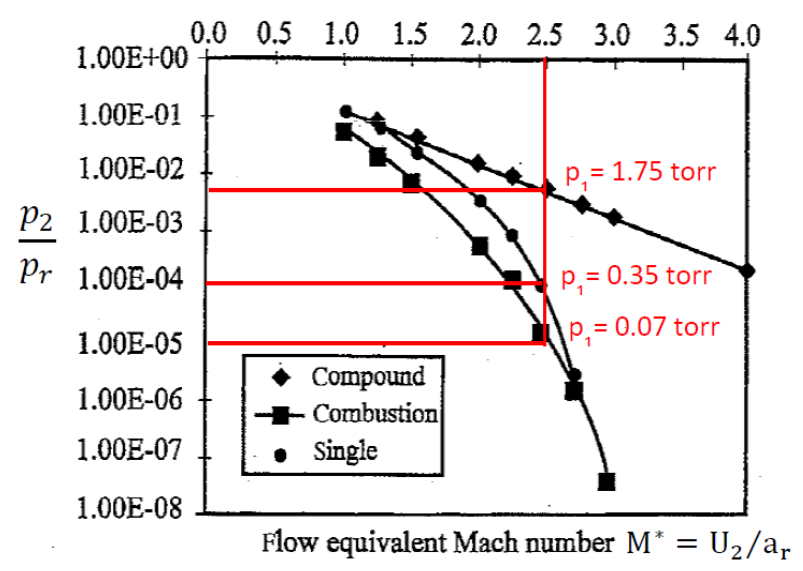

Figure 7. Comparison of the ratio of shock heated gas pressure to rupture pressure ratio as a function of flow equivalent Mach number for different driver choices.

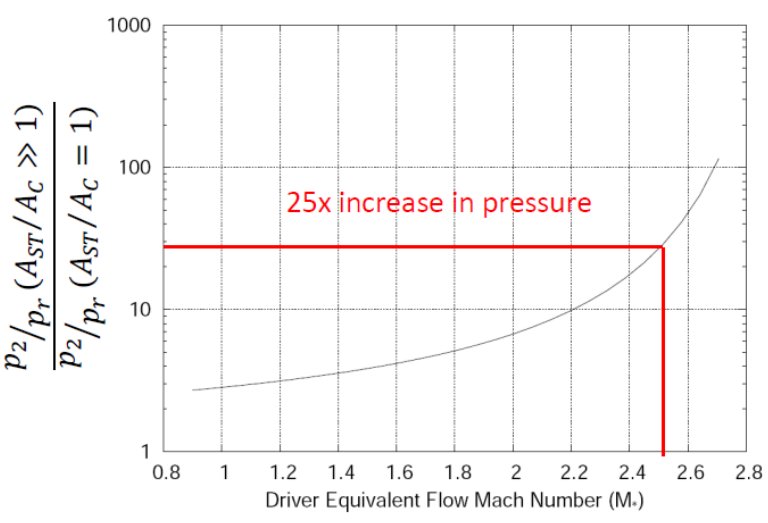

Figure 8. Performance increase when there is an area change at the primary diaphragm station as a function of driver equivalent Mach number adapted from [8].

At rupture, it is desirable to over drive the piston so that the driver pressure rises to $\sim 10 \%$ above the rupture pressure thereby maximising the effective driver length. For a noble driver gas $(\gamma=1.67)$ and an area change at the primary diaphragm, the ratio of the piston speed at rupture to the required gas velocity $\left(k=u_{r} / U_{r}\right)$ should be approximately 1.4 [7]. Referring to Figure 9, the hold time is then defined as the time between rupture and the pressure dropping to $10 \%$ below the rupture pressure. For the driver condition explored above, the piston speed at rupture is set to $203 \mathrm{~m} / \mathrm{s}$ giving a hold time of $0.28 \mathrm{~ms}$. Using the theory derived by Tanno et al. [9], the $36 \mathrm{~kg}$ piston with a $76.2 \mathrm{~mm}$ orifice plate (the original shock tube dimension for T3) should fall into the soft impact region ensuring the usefulness of the condition (Fig. 10). 


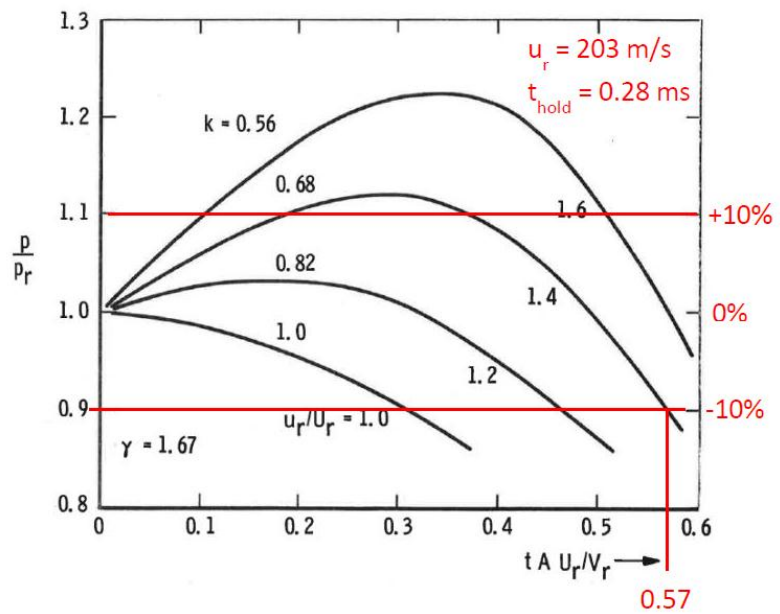

Figure 9. Hold time for T6 free piston driver at a rupture pressure of $50 \mathrm{MPa}$ and a volumetric compression ratio of 60, adapted from [7].

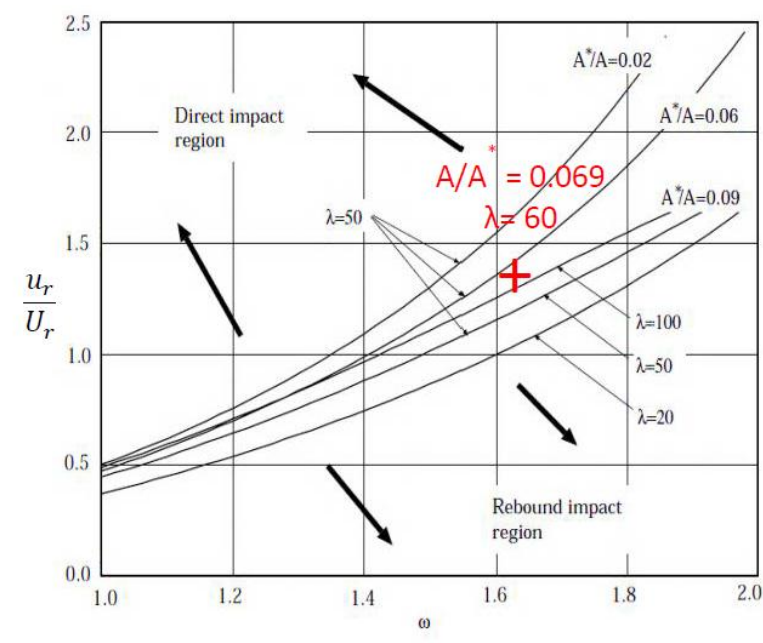

Figure 10. Soft landing for T6 free piston driver at a rupture pressure of $50 \mathrm{MPa}$ and a volumetric compression ratio of 60, adapted from [9].

\section{MODES OF OPERATION}

As described previously, the T6 facility has been designed to allow for operation as either a reflected shock tunnel, an expansion tunnel (both of which are for testing of models) or as a shock tube for shock layer radiation studies. The requirements of the experiment, as given by the desired flow velocity, density and the binary scaling parameter $(\rho L)$, will dictate the mode of operation. For speeds in the range 2 to $6 \mathrm{~km} / \mathrm{s}$, such as for scramjet engines, the facility can be operated in reflected shock tunnel mode. Above $6 \mathrm{~km} / \mathrm{s}$, like that required for re-entry vehicle simulation, the facility can be operated in expansion tunnel model. Tests that require longer flow durations at speeds above $4 \mathrm{~km} / \mathrm{s}$ but that can accept a test gas that is chemically contaminated may be conducted using the shock tube mode of the facility. Each of these different operating modes is discussed in the following sections and is summarised in Table 2.

Table 2: Summary of major properties of the T6 Stalker Tunnel for the different modes of operation.

\begin{tabular}{|l|c|c|c|}
\hline $\begin{array}{l}\text { Mode of } \\
\text { Operation }\end{array}$ & $\begin{array}{c}\text { Reflected } \\
\text { Shock } \\
\text { Tunnel }\end{array}$ & $\begin{array}{c}\text { Expansion } \\
\text { Tunnel }\end{array}$ & $\begin{array}{c}\text { Shock } \\
\text { Tube }\end{array}$ \\
\hline Testing type & $\begin{array}{c}\text { Subscale } \\
\text { model }\end{array}$ & $\begin{array}{c}\text { Subscale } \\
\text { model }\end{array}$ & $\begin{array}{c}\text { Shock layer } \\
\text { radiation }\end{array}$ \\
\hline Test duration $[\mu \mathrm{s}]$ & $1000-3000$ & $50-500$ & $2-50$ \\
\hline $\begin{array}{l}\text { Flow core } \\
\text { diameter }[\mathrm{mm}]\end{array}$ & $150-200$ & $50-120$ & 80 or 200 \\
\hline $\begin{array}{l}\text { Max flow speed } \\
{[\mathrm{km} / \mathrm{s}]}\end{array}$ & 6.5 & 15 & 18 \\
\hline
\end{tabular}

\subsection{Reflected shock tunnel mode}

A reflected shock tunnel operates by shock heating the test gas through both an incident and reflected shock process. A typical distance-time diagram of this mode of operation is shown in Fig. 11. As the test gas is brought its stagnation conditions, both the total enthalpy and total pressure achievable in this mode are limited by structural and free stream chemistry concerns. For the T6 facility, the maximum speed capability is approximately $6.5 \mathrm{~km} / \mathrm{s}$ for air. This mode of operation is primarily of interest for air breathing applications. Fig. 12 show that T6 is capable of matching unit Reynolds number across a wide range of total temperatures across the air breathing corridor up to Mach 10 (Fig. 2). T6 is comparable to other University scale facilities around the world including T4 (UQ), T5 (Caltech) and HELM (UniBw). Currently, it is planned to adapt the old Oxford Gun Tunnel nozzles (Mach 7 and Mach 8, designed for perfect gas) for operation at high enthalpies by changing the throat material.

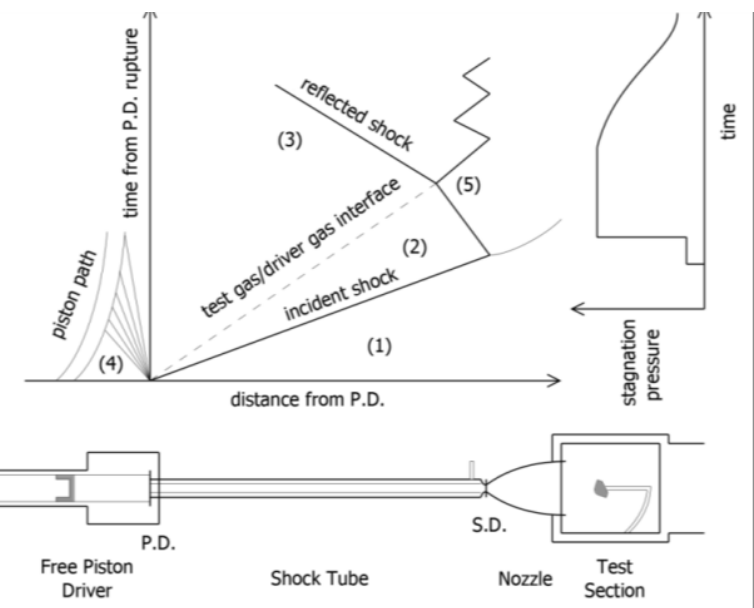

Figure 11: Distance-time diagram of T6 operated in reflected shock tunnel mode. 


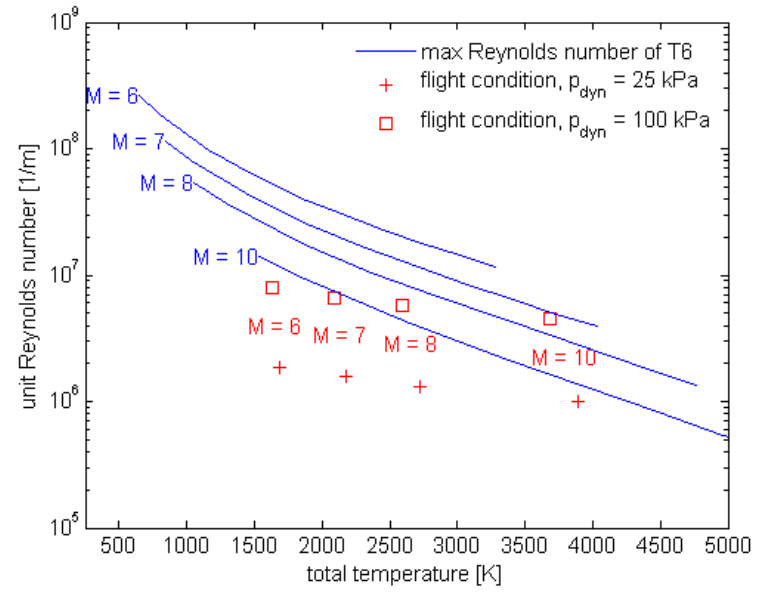

Figure 12: Unit Reynolds capability of the T6 facility at different total temperatures assuming equilibrium chemistry,

\subsection{Expansion tunnel mode}

In an expansion tunnel the test gas is initially shock heated before then undergoing an unsteady expansion. A further steady expansion at the end of the process can be used to increase the diameter of the core flow. A typical distance-time diagram of the expansion tunnel mode is shown in Fig. 13. Through the unsteady expansion the test gas undergoes a multiplication of its total enthalpy \& total pressure. The multiplication factor increases with the expanded Mach number. Since the test gas stagnation conditions are never realised, the structural limitations encountered in reflected shock tunnels are removed. Additionally, the test gas never reaches a high static temperature resulting in a chemically clean test flow. However, this comes at the expense of test time, which is limited to $10-100 \mu$ s. T6 is similar in size and performance to the $\mathrm{X} 2$ facility at UQ, though smaller than HyPULSE (GASL), LENSXX (CUBRC) and the X3 (UQ). A nozzle has yet to be designed for $\mathrm{T} 6$ for this mode of operation, though desired exit would be $280 \mathrm{~mm}$ in diameter.

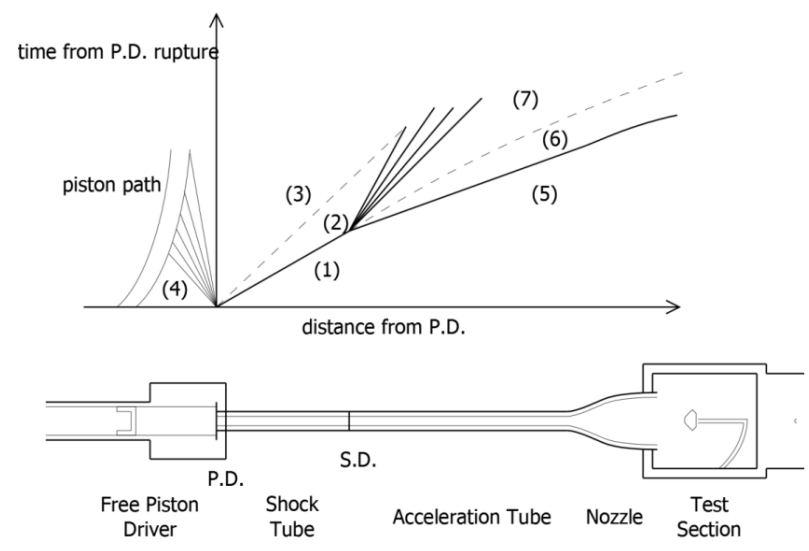

Figure 13: Distance-time diagram of T6 operated in expansion tunnel mode.
Fig. 14 presents the maximum predicted $\rho \mathrm{L}$ performance of the T6 facility when reproducing Earth re-entry conditions. The calculations were performed using the PITOT code [10] assuming chemical equilibrium and the previously investigated driver condition (Section 4.1). We are therefore assuming that the effective driver length is sufficient for these conditions. It can be seen from Figure 14 that T6 can reproduce the speeds and $\rho \mathrm{L}$ parameter requirements for both lunar return and asteroid return missions in expansion tunnel mode. This will ensure most parameters, including shock stand-off, convective heating and chemistry are scaled correctly. However, as radiation does not scale with $\rho \mathrm{L}$ and the model will be significantly smaller than in flight $(\sim 100 \mathrm{~mm}$ in diameter), scaling laws such as those applied by Capra et al. [11] will need to be applied to correctly understand the wind tunnel results.

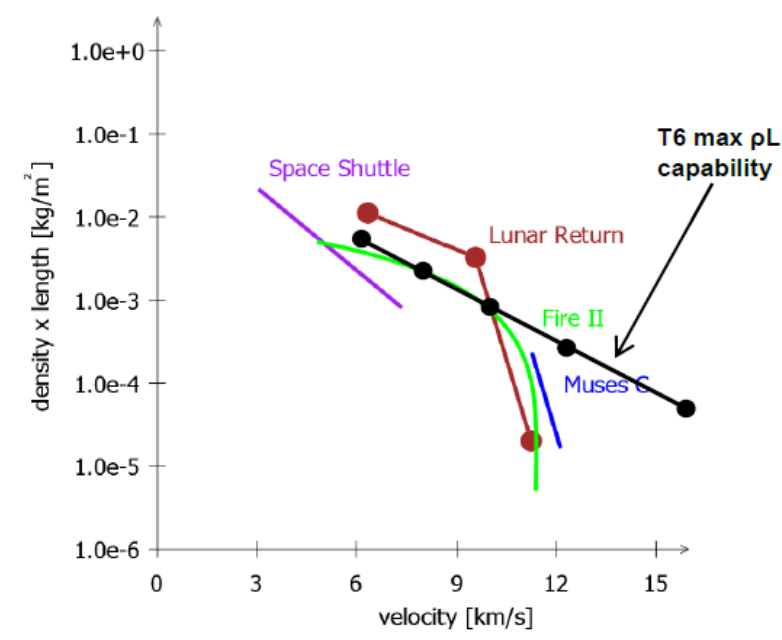

Figure 14: Capability of the T6 facility in expansion tunnel mode to simulate conditions for earth re-entry missions assuming equilibrium chemistry.

\subsection{Shock tube mode}

The shock tube mode of operation is setup particularly to undertake shock layer radiation experiments. Initially the shock tube is filled with test gas to the density equivalent pressure of the flight condition of interest. A shock is then passed through the test gas at the spacecraft flight speed, generating the same radiation emission that would be experienced on the stagnation streamline. In this configuration, a secondary driver can be used to increase the performance of the free-piston driver (as discussed previously). Fig. 15 presents the distance-time diagram for this mode of operation, where the measurement of the shock layer radiation can be taken through the wall of the extension tube which is connected directly to the dumptank. 

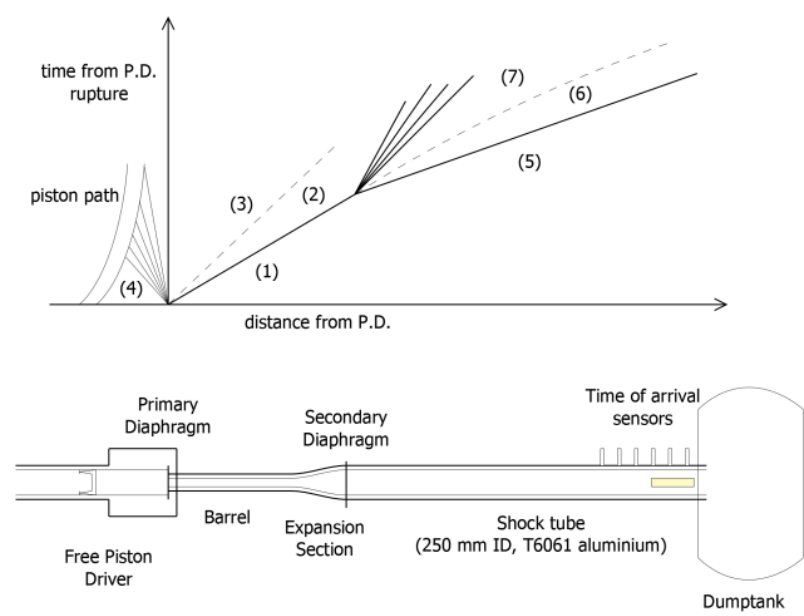

Figure 15: Distance-time diagram of T6 operated in shock tube mode with $250 \mathrm{~mm}$ diameter shock tube.

The T6 facility is similar in size to the NASA EAST and UQ X2 facilities though should be capable of generating much faster shock speeds. This may permit an increase in shock tube diameter to $250 \mathrm{~mm}$, thereby allowing investigation of low radiation conditions such as those experienced at high altitude [12] or at slow speeds [13]. In these instances, radiation is still of importance for large spacecraft (i.e. deployable structures). This would also permit the use of an aluminium shock tube with the T6 aluminium dumptank, thus removing all sources of contaminants. The maximum pressure capability of the facility in shock tube mode was again investigated for Earth reentry conditions using the PITOT code. The results are shown in Fig. 16. Again the driver condition discussed previously was used but with the addition of a $20 \mathrm{kPa}$ Helium secondary driver. From Fig. 16 it can be seen that when using a straight through $96.3 \mathrm{~mm}$ tube

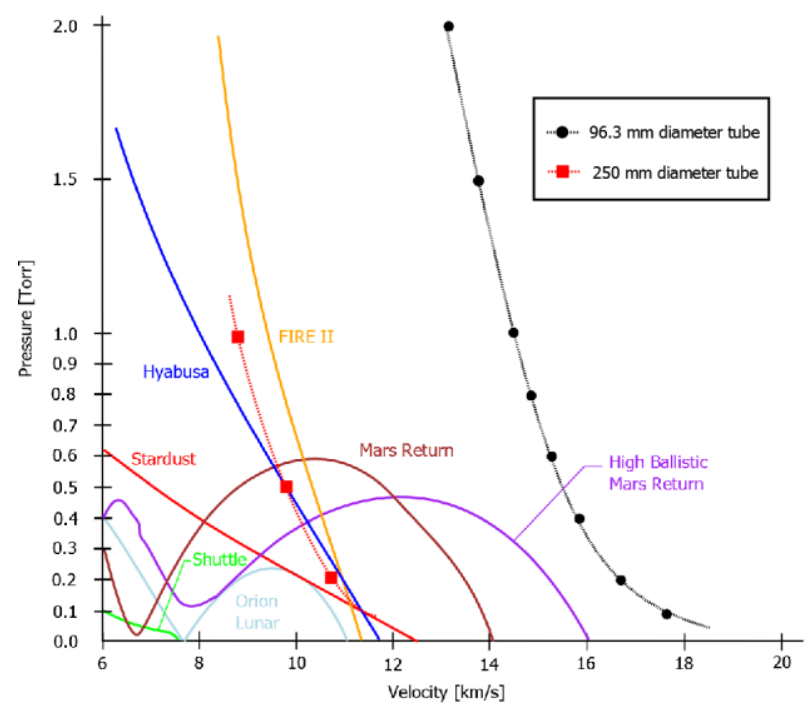

Figure 16: Capability of T6 facility in shock tube mode to simulate Earth re-entry conditions (adapted from [14]) diameter the facility can easily produce shock speeds for all relevant conditions. If a larger $250 \mathrm{~mm}$ diameter was applied, both Moon return and all Mars entry conditions of interest (not shown) can be achieved. L1d simulations [14] of the T6 facility for a $133 \mathrm{~Pa}$ (1 torr) fill pressure have indicated that the transient wave processes do not affect the shocked test gas, and the predicted shock speed is achievable (Fig. 17).

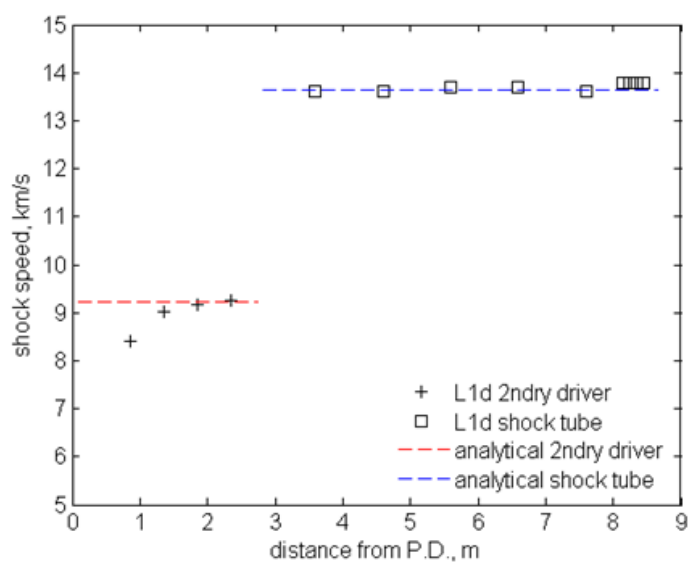

Figure 17: Shock speed for 133 Pa air shock tube condition assuming equilibrium chemistry.

\section{INFRASTRUCTURE}

Below is a brief description of the surrounding facility infrastructure:

Compressor - Gardner Denver 54371A, 350 bar with dryer, $145 \mathrm{~m}^{3} / \mathrm{hr}$

High Pressure air storage - 3000 L volume, 275 bar air storage

PLC Operation - GE Mitchell bespoke design

Test Section - old gun tunnel test section, $1.1 \times 0.9 \mathrm{x}$ $0.9 \mathrm{~m}$

Dumptank - stainless steel tank with 3200 L volume, max pressure of 2 bar

Vaccum - Edwards GXS 600/1750 Dry screw pump with booster

Turnaround of Piston - Motor driven rack and pinion for pushing piston back, hydraulic driven cross slides to move shock tube, hydraulic driven axial movement

Fill pressure instrumentation - GEMS pressure transducers, Edwards ASG active strain gauges \& Inficon capacitance diaphragm gauges

Tunnel instrumentation - ceramic coated $\mathrm{PCB}$ in nozzle stag, PCB-113 in main length of shock tube for shock timing and PCB-132 in shock tube mode for high response shock speed measurement. 


\section{DAQ \& INSTRUMENTATION}

Below is a brief description of the instrumentation and data acquisition system:

High speed pressure - PCB 132 high speed transducers, Kulite XTL-140 high speed transducers

High speed video - Specialised Imaging Kirana (5 MHz for 250 frames) \& Photron Mini UX-100 (1 MHz, reduced capture window, 3 seconds) and $1 \mathrm{MHz}$ LED light source

High speed heat transfer - In-house thin film signal conditioning, HTA3 \& HTA4.

DAQ - National Instruments PXE-8135 withseveral PXIE-6368 (2 Hz/channel) \& PXIE-6363 cards (2 MHz aggregate). Free-flight DAQ system, 6 channels, $20 \mathrm{kHz}$ with signal conditioning.

Oscilloscope -Teledyne Lecroy $5 \mathrm{GHz}, 4$ channel.

Laser - Continuum Powerlite ND-YAG laser, Low noise Oxxium DPSS $532 \mathrm{~nm}$ and Laser Quantum DPSS $671 \mathrm{~nm}$.

\section{CONCLUSION}

The T6 Stalker tunnel will be a multi-mode facility capable of producing flow conditions that replicate high speed atmospheric entry. In particular, for radiation experiments, the T6 facility can be operated as an expansion tunnel to test subscale vehicle models or as a shock tube to investigate shock layer radiation. The facility is currently under final design review, with most of the infrastructure in place. It is currently planned that commissioning of the facility will begin in mid-late 2015 .

\section{REFERENCES}

1. Fletcher, D.G. (2004). Fundamentals of Hypersonic Flow - Aerothermodynamics. RO AVT Lecture Series, RTO-EN_AVT-116.

2. Morgan, R.G. (2014). “Hooray for Ray,” Plenary presentation, 11th AIAA/ASME Joint Thermophysics and Heat Transfer Conference.

3. Mathews, A.J., Jones, T.V. and Cain, T.M. (2005). Design and test of a Hypersonic Isentropic-Spike Intake with Aligned Cowl," AIAA Journal of Propulsion and Power, 21 (5), 2005.

4. Morris, N.A. (1995). An experimental and computational study of moderately underexpanded rocket plumes in a co-flowing hypersonic free stream. DPhil Thesis, University of Oxford.

5. Smith, A.J., Paranby, G.D., Matthews, A.J. \& Jones, T.V.(2002). Aerothermodynamic Environment of the Beagle2 Entry Capsule. Proceedings of the 4th European Symposium on Aerothermodynamics for Space Applications.

6. Editors (1963). A gun tunnel for research at 7000 mph. New Scientist (338), 319.

7. Stalker, R. J. \& Besant, R. W. (1959). A Method for Production of Strong Shocks in a Gas Driven Shock Tube. Report No. GD-81 National Research Council, Ottawa, Canada.

8. Stewart, B. (2004). Predicted Scramjet Testing Capabilities of the Proposed RHYFL-X Expansion Tube. PhD Thesis, University of Queensland.

9. Tanno, H., Itoh, K. \& Sato, K. (2000). Experimental study on the tuned operation of a free piston driver. Shock Waves, 10, 1-7.

10. James, C.M., Gildfind, D.E., Morgan, R.G., Jacobs, P.A. \& Zander, F. (2013) Designing and Simulating High Enthalpy Expansion Tube Conditions. Asia-Pacific International Symposium on Aerospace Technology.

11. Capra, B.R., R. G. Morgan, R.G. \& P. Layland, P. (2004). Heat Transfer Measurements of the First Experimental Layer of the Fire II Re-entry Vehicle in Expansion Tubes. Proceedings of the fifth European Symposium on Aerothermodynamics for Space Vehicles (ESA SP-563).

12. Jacobs, C. (2014). Radiation in Low Density Flows. Joint $\mathrm{PhD}$ thesis, University of Queensland and Ecole Cenrale Paris.

13. Cruden, B.A. Prabhu, D.K. \& Brandis, A.M. (2014). Measurement and Characterization of Midwave Infrared Radiation in CO2 Shocks. AIAA Paper 2014-2962, 11th AIAA/ASME Joint Thermophysics and Heat Transfer Conference.

14. Jacobs. P.A. (1998). Shock Tube Modelling with L1d. Report 13/98, Dept. of Mechanical Engineering, University of Queensland.

15. Brandis, A.M. \& Johnston, C.O. (2014). Characterization of Stagnation-Point Heat Flux for Earth Entry. AIAA Paper 2014-237411th AIAA/ASME Joint Thermophysics and Heat Transfer Conference. 